\title{
Freqüência de Doenças Reumáticas em Indivíduos Infectados pelo HTLV-1
}

\section{Frequency of Rheumatic Diseases in Individuals Infected with HTLV-1}

\author{
Mônica Martinelli Nunes de Carvalho(1), Silvana Pereira Giozza ${ }^{(2)}$, André Luiz Muniz Alves dos Santos( ${ }^{(3)}$, \\ Edgar Marcelino de Carvalho ${ }^{(4)}$, Maria Ilma Araújo(5)
}

\section{RESUMO}

Introdução: o HTLV-1 é um retrovírus humano associado à leucemia de células $\mathrm{T}$ do adulto e à mielopatia associada ao HTLV-1 ou paraparesia espástica tropical, que tem sido implicado também no desenvolvimento de auto-imunidade. Objetivo: o objetivo deste estudo foi determinar a freqüência de doenças reumáticas autoimunes em pacientes infectados pelo HTLV-1. Pacientes e Métodos: foram incluídos nesse estudo 137 indivíduos infectados pelo HTLV-1 atendidos no Ambulatório Multidisciplinar do Serviço de Imunologia do Hospital Universitário Professor Edgard Santos (HUPES) da Universidade Federal da Bahia (UFBA), no período de janeiro de 2003 a maio de 2004 . Os pacientes responderam a um questionário geral relacionado a manifestações reumatológicas e questionários específicos para confirmação dos critérios diagnósticos de artrite reumatóide (AR), lúpus eritematoso sistêmico (LES), síndrome de Sjögren e polimiosite. Adicionalmente, todos eles foram submetidos a exames clínicos específicos e avaliação complementar. Resultados: 24 pacientes tiveram o diagnóstico de síndrome de Sjögren (SS) provável (17,5\%), 18 pacientes $(13,1 \%)$ de AR, uma paciente teve diagnóstico de LES e uma de doença mista do tecido conjuntivo $(0,7 \%$, respectivamente). Suspeita de artropatia relacionada ao vírus foi encontrada em 22 pacientes (16,1\%). Síndrome de Sjögren e AR foram mais freqüentes nos pacientes com mielopatia ( 33,3 e $25,9 \%$, respectivamente) do que nos portadores assintomáticos (13,6 e 10\%, respectivamente). Artropatia relacionada ao HTLV-1 ocorreu com freqüência semelhante em ambos os grupos. Conclusão: foi observado neste trabalho alta prevalência de síndrome de Sjögren e de AR entre os indivíduos infectados pelo HTLV-1, principalmente naqueles com mielopatia. Diante desses resultados, que reforçam os dados da literatura, deve-se estar atento para a ocorrência de doenças reumáticas auto-imunes nesses pacientes.

Palavras-chave: HTLV-1, doenças difusas do tecido conjuntivo, doenças reumáticas auto-imunes.

\begin{abstract}
Introduction: the HTLV-1 is a human retrovirus associated with adult T-cell leukaemia (ATL) and with HTLV-1-associated myelopathy or tropical spastic paraparesis, which has also been implicated in the development of autoimmunity. Objective: the aim of this study was to determine the frequency of autoimmune rheumatic diseases in patients infected with HTLV-1. Patients and Methods: it was included 137 individuals infected with HTLV-1 from the Multidisciplinary Ambulatory of Immunology Service, HUPES-UFBA, Salvador (BA), from January 2003 to May 2004. All participants answered to a general questionnaire regarding rheumathological manifestations and specific questionnaires to confirm the diagnose criteria of rheumatoid arthritis (RA), systemic lupus erythematosus (SLE), Sjögren's syndrome (SS) and polymyositis. Additionally, they were submitted to specific clinical exams, besides complementary evaluations. Results: 24 patients had diagnose of probable Sjögren's syndrome (17.5\%), 18 patients (13.1\%) had RA, one patient had diagnose of SLE $(0.7 \%)$ and another of mixed connective tissue disease (0.7\%, respectively). HTLV-1-associated arthropathy (HAAP) was suspected in 22 individuals (16.1\%). Sjögren's syndrome and $R A$ were more frequent in patients with myelopathy (33.3 and $25.9 \%$, respectively) than in asymptomatic carriers (13.6 and $10 \%$, respectively). The frequency of HTLV-1-associated arthropathy was the same in both groups. Conclusion: in this study it was observed a high frequency of Sjögren's syndrome and $R A$ in individuals infected with HTLV-1, mainly in those with myelopathy. Therefore, with this results that support data in the literature, we should call attention to the occurrence of autoimmune rheumatic diseases in these kind of patients.
\end{abstract}

Keywords: HTLV-1, difuse connective tissue diseases, autoimmune rheumatic diseases.

Serviço de Imunologia do Hospital Universitário Professor Edgard Santos (HUPES), Universidade Federal da Bahia (UFBA). Recebido em 05/05/06. Aprovado, após revisão, em 24/07/06.

1. Professora substituta da UFBA, Especialista em Reumatologia e Mestre em Imunologia.

2. Pesquisadora do Serviço de Imunologia do HUPES da UFBA

3. Pesquisador do Serviço de Imunologia do HUPES da UFBA.

4. Professor Livre Docente da UFBA, Chefe do Serviço de Imunologia do HUPES

5. Professora Adjunta da Escola Bahiana de Medicina e Saúde Pública e Pesquisadora do Serviço de Imunologia do HUPES da UFBA

Endereço para correspondência: Mônica Martinelli Nunes de Carvalho, Serviço de Imunologia do Hospital Universitário Professor Edgard Santos, Rua João das Botas, s/n, Canela, CEP 40110-160, Salvador, BA, Brasil, telefone: (71) 3237-7353, fax: (71) 3245-7110, e-mail: monicamartinelli@atarde.com.br 


\section{INTRODUÇÃO}

Estudos sugerem o envolvimento do HTLV-1 como agente desencadeador e perpetuador das doenças inflamatórias articulares crônicas ${ }^{(1)}$. Nishioka et al ${ }^{2)}$, em 1991, foram os primeiros autores a propor uma associação entre HTLV-l e artrite reumatóide (AR), baseando-se na observação de que indivíduos infectados de HTLV-1 com e sem mielopatia, apresentavam artropatia crônica inflamatória. Num estudo realizado em Nagasaki, área endêmica para infecção pelo HTLV-1, a soroprevalência desse vírus em mulheres com AR foi de $20,4 \%$, significativamente maior do que nas mulheres doadoras de sangue $(4,2 \%)^{(1)}$. Motokawa et al, em $1996^{(3)}$, demonstraram também que a prevalência de AR entre os pacientes soropositivos para o HTLV-1 foi de $0,56 \%$, significativamente maior que na população soronegativa $(0,31 \%$; $\mathrm{p}<0,05)$. O mecanismo proposto foi de que os linfócitos infectados produziriam maior quantidade de citocinas, tais como interleucinas (IL) IL-1 beta e IL-6 e fator de necrose tumoral alfa (TNF-A), que participariam do processo inflamatório, estimulando a proliferação das células sinoviais. A detecção de produtos genéticos do HTLV-1 não somente em células mononucleares, mas também em células do estroma sinovial $^{(4)}$, sugere tropismo deste vírus pelo tecido sinovial.

Vernant et $a l^{(5)}$, em 1988, foi quem primeiro propôs uma associação entre HTLV-1 e síndrome de Sjögren (SS). O referido autor tomou como base o fato de que pacientes infectados pelo HTLV-1 associados à mielopatia/paraparesia espástica tropical (MAH/PET) comumente desenvolviam sintomas semelhantes aos que ocorrem na SS. Eguchi et $a^{(6)}(1992)$ e Terada et $a l^{7)}$ (1994), posteriormente, reportaram alta soroprevalência de HTLV-1 entre pacientes com SS em área endêmica para HTLV-1 (a razão de chances de infecção pelo HTLV-1 ajustada pela idade entre pacientes com SS doadores de sangue foi 3:1).

Diversos estudos têm demonstrado que o HTLV-1 induz no sistema imune uma resposta proliferativa linfocitária exuberante e, mais recentemente, que células de portadores desse vírus secretam altos níveis de IFN-G TNF-A, IL-5 e IL-10 in vitro, na ausência de estímulo, comparados com células de doadores de sangue soronegativos para o HTLV$1^{(8)}$. Desta forma, o HTLV-1 tem sido implicado na indução de auto-imunidade e assim justificando a maior freqüência de doenças reumáticas auto-imunes nesses pacientes. No Brasil, particularmente, na cidade de Salvador (BA), a prevalência da infecção pelo HTLV-1 é de aproximadamente 1,8\%, uma das maiores do país ${ }^{(9)}$, constituindo uma área endêmica importante, o que permitiu o desenvolvimento desse estudo pioneiro que determina a freqüência das principais doenças reumáticas auto-imunes em uma população de pacientes infectados pelo HTLV-1 e os possíveis mecanismos que levam ao aparecimento dessas doenças.

\section{MATERIAL E MÉTODOS}

\section{CARACTERÍSTICAS DA POPULAÇÃO E SELEÇÃO DOS PACIENTES}

A população desse estudo é formada por indivíduos de quaisquer idades, de ambos os gêneros, infectados pelo HTLV-1, atendidos no Ambulatório de HTLV do Hospital Universitário Professor Edgard Santos (HUPES), no período de janeiro de 2003 a maio de 2004 . A população estudada foi dividida em dois grupos: o primeiro deles formado por pacientes com manifestações articulares e/ou doenças reumáticas auto-imunes, identificados a partir de questionários gerais e específicos, e o segundo por indivíduos sem manifestações articulares. Os participantes do estudo também foram divididos em infectados pelo HTLV-l assintomáticos neurológicos e aqueles com mielopatia associada ao vírus (MAH). Para o diagnóstico de mielopatia associada ao HTLV-1 foram utilizados os critérios da Organização Mundial de Saúde (OMS). A Escala Expandida do Estado de Incapacidade de Kurtzke (EDSS) ${ }^{(10)}$ foi utilizada para confirmar que a limitação motora do paciente era por uma alteração neurológica. Portanto, foram considerados portadores de mielopatia, os indivíduos com EDSS maior ou igual a três, com função piramidal alterada maior ou igual a dois e líquor com sorologia positiva para HTLV-1.

\section{APLICAÇÃO DE QUESTIONÁRIOS PARA A SELEÇÃO DOS PACIENTES}

Após a identificação dos pacientes infectados pelo HTLV-1, por ordem de matrícula no ambulatório, os mesmos foram atendidos por uma equipe multidisciplinar e encaminhados para avaliação reumatológica, objeto desse estudo, para aplicação de questionário dirigido, exame físico geral e reumatológico e avaliação diagnóstica complementar.

Para confirmação diagnóstica das doenças reumáticas, também foram aplicados questionários específicos, de acordo com os critérios de classificação propostos pelos seguintes grupos: Grupo Europeu - Americano para $\mathrm{SS}^{(11)}$, que baseia-se na presença de pelo menos quatro dos seis critérios, cuja sensibilidade e especificidade são de $97,4 \%$ e $89,4 \%$, respectivamente; American College of 
Rheumatology (ACR) para LES, que baseia-se na presença de pelo menos 4 dos 11 critérios ${ }^{(12,13)}$; Associação Americana de Reumatismo, revisado em 1988, que toma por base a presença de quatro dos sete critérios para classificação de $\mathrm{AR}$, porém pacientes com dois ou três critérios não são excluídos $^{(14)}$. Contudo, não foram considerados para a inclusão neste protocolo os critérios propostos por Targoff \& Miller, em $1997^{(15)}$, para polimiosite, através dos quais a presença de dois critérios indica diagnóstico possível, de três critérios, diagnóstico provável e de quatro critérios, diagnóstico definido.

A partir dessa seleção, ressalvados os critérios de exclusão referidos a seguir, os pacientes foram admitidos no estudo por ordem de atendimento ambulatorial. Foram excluídos do estudo pacientes portadores de leucemia ou linfoma, co-infectados por vírus C da hepatite e/ou HIV, por serem condições que podem apresentar manifestações semelhantes.

Antes de entrar no estudo, todos os participantes foram informados sobre a natureza da pesquisa, a voluntariedade na participação e os prejuízos e benefícios oriundos desse projeto de pesquisa. A voluntariedade na participação desse projeto foi feita mediante assinatura dos pacientes ou seus representantes legais, do termo de consentimento livre e esclarecido. Esse estudo obteve a aprovação do Comitê de Ética em Pesquisa do HUPES.

\section{AVALIAÇÃO LABORATORIAL}

Títulos de anticorpos anti-HTLV-1 foram determinados no soro dos pacientes, através da técnica de ELISA (Cambridge Biotech Corp, Worcester, MA, USA) pelo Serviço de Imunologia do HUPES da UFBA. Amostras positivas foram, então, submetidas à confirmação e discriminação entre HTLV-1 e HTLV-2 através da técnica de Western Blot (HTLV Blot 2.4, Genelabs, Science Park Drive, Singapore). Os resultados foram interpretados de acordo com as instruções do fabricante.

Também foram pesquisados através da técnica de ELISA, no STS, HEMOBA e Laboratório de Hepatologia e de Retrovírus do HUPES, os seguintes marcadores virais: AgHbs, anti-HBs, anti-HBc, anti-HCV, anti-HIV-1 e anti-HIV-2.

A pesquisa de fator reumatóide (FR) com $\operatorname{IgG}$ e IgM foi realizada através da técnica de ELISA. O fator antinúcleo (FAN) foi analisado pela técnica de imunofluorescência indireta, utilizando cultura de células HEp-2 e anticorpos anti-SS-A (Ro) e SS-B (La), através da técnica de ELISA.
Pesquisa de anticorpo anticitrulina (anti-CCP) foi realizada pela técnica de ELISA, tendo sido consideradas negativas as amostras com resultados menores ou iguais a 25 unidades/ $\mathrm{mL}$ e positivos, os valores acima de 50 unidades $/ \mathrm{mL}$. Os resultados entre 25 e 50 unidades/mL foram considerados duvidosos, sendo recomendada a repetição do exame após determinado período de tempo. Esses exames foram realizados em laboratório privado.

\section{ANÁLISE ESTATÍSTICA}

A amostra estudada foi selecionada na medida em que se delimitou o período de inclusão de pacientes no estudo (janeiro de 2003 a maio de 2004). Os dados coletados foram armazenados em banco de dados padronizado, do programa SPSS 9.0 para a análise de estatística descritiva, tais como: valor mínimo, valor máximo, média, mediana, desvio padrão, freqüências relativas e acumuladas, de comparação de proporções através dos testes de Qui-quadrado, e em casos específicos, utilizado o teste de Fisher através do programa Graph pad Instat. A análise de comparação de médias foi feita através do teste $t$ de Student. Foi considerado significativo um valor de $\mathrm{p}<0,05(\mathrm{~A} \# 5 \%$ ).

\section{RESULTADOS}

\section{CARACTERÍSTICAS DEMOGRÁFICAS E APRESENTAÇÃO CLÍNICA DO HTLV-1 NA POPULAÇÃO ESTUDADA}

No período de 16 meses em que o estudo foi conduzido, foram selecionados 149 indivíduos infectados pelo HTLV-1, dos quais 12 foram excluídos: 11 por apresentarem sorologia positiva para HCV e um para HIV, resultando, portanto, em 137 indivíduos (Tabela 1). Desses, 82 eram do gênero feminino $(59,9 \%)$ e 55 do gênero masculino $(40,1 \%)$, com idades variando entre 20 a 80 anos (média $=45,9$ ).

Dos 137 indivíduos infectados pelo HTLV-1 que participaram do estudo, 110 eram assintomáticos do ponto de vista neurológico. Desses, $58,1 \%$ pertenciam ao gênero feminino, e a idade variou de 36 a 71 anos, com média e desvio padrão de 44,2 \pm 12 . Os outros 27 pacientes apresentavam mielopatia associada ao vírus (MAH/PET). Desses, 18 foram do gênero feminino $(66,6 \%)$ e nove do gênero masculino $(33,4 \%)$. A idade variou entre 20 a 80 anos, sendo a média de idade e o desvio padrão de $52,7 \pm 8,9$. Foi observada diferença significativa na média de idade entre os grupos de indivíduos assintomáticos e aqueles com mielopatia $(\mathrm{p}=0,001)$. 
TABELA 1

CARACTERÍSTICAS DEMOGRÁFICAS DE 137 INDIVÍDUOS INFECTADOS PELO HTLV-I, ATENDIDOS NO HUPES DA UFBA

\begin{tabular}{|c|c|c|c|c|c|c|c|}
\hline \multirow[t]{2}{*}{$\begin{array}{l}\text { Características } \\
\text { demográficas }\end{array}$} & \multicolumn{2}{|c|}{$\begin{array}{l}\text { HTLV-1 + } \\
(n=137)\end{array}$} & \multicolumn{2}{|c|}{$\begin{array}{c}\text { HTLV-1 + } \\
\text { sem mielopatia } \\
(n=110)\end{array}$} & \multicolumn{2}{|c|}{$\begin{array}{c}\text { HTLV-1 + } \\
\text { com mielopatia } \\
\quad(n=27)\end{array}$} & \multirow[t]{2}{*}{$\begin{array}{l}\text { Valor } \\
\text { de } p\end{array}$} \\
\hline & $\mathrm{n}$ & $\%$ & $\mathrm{n}$ & $\%$ & $\mathrm{n}$ & $\%$ & \\
\hline \multicolumn{8}{|l|}{ Gênero } \\
\hline Feminino & 82 & 59,9 & 64 & 58,1 & 18 & 66,6 & \multirow{2}{*}{$0,420^{1}$} \\
\hline Masculino & 55 & 40,1 & 46 & 41,9 & 9 & 33,4 & \\
\hline Média de Idade (anos) $\pm \mathrm{DP}$ & \multicolumn{2}{|c|}{$45,9 \pm 11,9$} & \multicolumn{2}{|c|}{$44,2 \pm 12$} & \multicolumn{2}{|c|}{$52,7 \pm 8,9$} & \multirow{2}{*}{$0,001^{2}$} \\
\hline Limites & & |ा| 80 & 36 & 71 & 20 & 80 & \\
\hline
\end{tabular}

${ }^{1}$ Teste do Qui-quadrado. Comparando pacientes com e sem mielopatia.

${ }^{2}$ Teste $t$ de Student. Comparando pacientes com e sem mielopatia.

\section{MANIFESTAÇÕES ARTICULARES NOS INDIVÍDUOS INFECTADOS PELO HTLV-1}

Manifestações de dor articular foram identificadas em 80 pacientes $(58,4 \%)$. Quanto ao número de articulações envolvidas, 10,2\% dos pacientes apresentavam monoartralgia, $16,8 \%$ apresentavam oligoartralgia, enquanto que poliartralgia foi relatada por $31,4 \%$ dos pacientes (Gráfico 1 ).

GrÁFICO 1

FREQÜÊNCIA DE MANIFESTAÇÕES ARTICULARES EM 137 INDIVÍDUOS INFECTADOS PELO HTLV-1 ATENDIDOS NO HUPES-UFBA

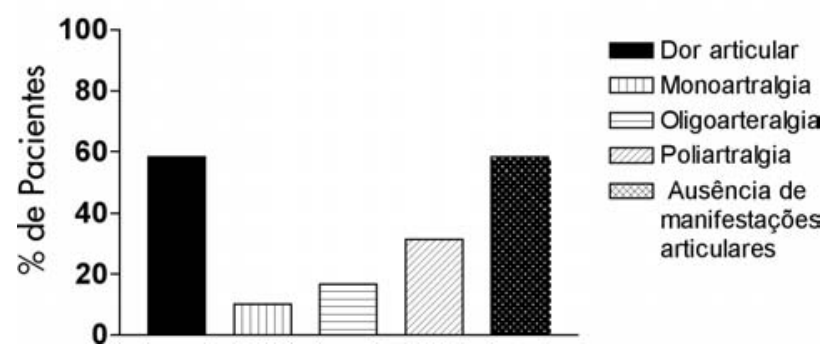

Envolvimento articular simétrico ocorreu em $35,8 \%$ dos pacientes, sendo que sinovite foi observada em 16,1\% dos casos. Rigidez articular matinal com duração igual ou acima de 60 minutos foi identificada em 19\% dos pacientes, e uma minoria deles $(5,8 \%)$ apresentava deformidades articulares (dado não mostrado).

A freqüência de articulações periféricas acometidas por manifestações reumatológicas é mostrada na Tabela 2. As articulações dos joelhos foram as mais envolvidas, ocorrendo em $38,7 \%$ dos pacientes, enquanto que em 16,9\% dos pacientes avaliados houve acometimento dos tornozelos.

Envolvimentos dos ombros e cotovelos foram identificados em 20,4 e 15,5\% dos pacientes, respectivamente. Artralgia envolvendo punhos e mãos ocorreu em 13,4 e $10,6 \%$ dos pacientes, respectivamente, e apenas um paciente $(0,7 \%)$ apresentava comprometimento das articulações dos pés (Tabela 2).

TABELA 2

ArTiculaÇões PERIFÉRICAS ENVOLVIDAS EM 80 INDivíduos INFECTADOS PELO HTLV-1

\begin{tabular}{ccc}
\hline $\begin{array}{c}\text { HTLV-1 }+(\mathbf{n}=\mathbf{8 0}) \\
\text { Articulações acometidas }\end{array}$ & $\mathbf{n}$ & $\%$ \\
\hline Joelhos & 55 & 38,7 \\
\hline Ombros & 29 & 20,4 \\
\hline Tornozelos & 24 & 16,9 \\
\hline Cotovelos & 22 & 15,5 \\
Punhos & 19 & 13,4 \\
Mãos & 15 & 10,6 \\
\hline Pés & 1 & 0,7 \\
\hline
\end{tabular}

\section{DOENÇAS REUMÁTICAS EM INDIVÍDUOS INFECTADOS} PELO HTLV-1

Utilizando os critérios clínicos e laboratoriais para diagnóstico de doenças reumáticas, observou-se que a SS provável foi a doença mais freqüente na população estudada, tendo ocorrido em 24 dos 137 indivíduos avaliados (17,5\%). A segunda doença reumática mais encontrada foi a AR, ocorrendo em 18 pacientes $(13,1 \%)$. Em um dos 137 pacientes, foi feito o diagnóstico de LES $(0,7 \%)$ e em uma outra foi diagnosticada doença mista do tecido conjuntivo - DMTC $(0,7 \%)$. A artropatia relacionada ao HTLV-1 (APAH) foi suspeitada em 22 pacientes (16,1\%), após a exclusão das diversas doenças reumáticas (Tabela 3 ).

Osteoartrite (OA) foi observada em 15 dos 137 indivíduos avaliados (10,9\%), e algumas síndromes dolorosas regionais, a exemplo de tendinite, bursite e epicondilite, foram também encontradas em $5,1 \%$ dos participantes do estudo. Manifestações articulares relacionadas a doenças sistêmicas, tais como tireoideopatias e anemia falciforme, foram evidenciadas em $4,4 \%$ dos pacientes avaliados. Nesses pacientes foram excluídas as associações com doenças reu- 
máticas primárias. Em uma paciente do estudo foi diagnosticada febre reumática (Tabela 3 ). Ausência de manifestações articulares foi observada em 51 dos 137 infectados pelo HTLV-1 (37,2 \%) que fizeram parte desse estudo.

TABELA 3

FreqüÊncia de Doenças Reumáticas em 137 indivíduos INFECTADOS PELO HTLV-1 ATENDIDOS NO HUPES-UFBA

\begin{tabular}{lcc}
\hline HTLV-1 + ( $\mathbf{n = 1 3 7 ) ~ / ~}$ & \multicolumn{2}{c}{ Freqüência } \\
Doenças Reumáticas & $\mathbf{n}$ & $\%$ \\
\hline Síndrome de Sjögren provável & 24 & 17,5 \\
\hline Artrite reumatóide & 18 & 13,1 \\
\hline Lúpus eritematoso sistêmico & 1 & 0,7 \\
\hline Doença mista do tecido conjuntivo & 1 & 0,7 \\
\hline Artropatia relacionada ao vírus & 22 & 16,1 \\
\hline Osteoartrite & 15 & 10,9 \\
\hline Manifestação articular de doença sistêmica & 6 & 4,4 \\
\hline Síndromes dolorosas regionais & 7 & 5,1 \\
\hline Febre reumática & 1 & 0,7 \\
\hline
\end{tabular}

MANIFESTAÇÕES ARTICULARES EM INDIVÍDUOS

INFECTADOS PELO HTLV-1 COM E SEM MIELOPATIA ASSOCIADA AO VÍRUS

Foi avaliada também nesse estudo a freqüência de manifestações articulares nos indivíduos infectados pelo HTLV-1, de acordo com a presença ou não de mielopatia. A freqüência de dor articular no grupo com mielopatia foi de $77,7 \%$, enquanto que no grupo sem manifestações neurológicas foi de $53,6 \%$, sendo essa diferença estatisticamente significativa - $\mathrm{p}=0,023$ (Tabela 4 ).

Em termos de número de articulações envolvidas, a poliartralgia foi a apresentação clínica mais comum, com uma freqüência de $59,2 \%$ nos pacientes com mielopatia e $24,5 \%$ nos infectados sem manifestação neurológica $(\mathrm{p}=0.000)$. Lombalgia foi relatada em $48,1 \%$ dos pacientes com mielopatia e em $26,3 \%$ dos infectados sem manifestação neurológica $(\mathrm{p}=0,028)$. Queixa de rigidez articular matinal com duração igual ou acima de 60 minutos ocorreu em 12 dos $27(44,4 \%)$ pacientes com mielopatia e em 14 dos $110(12,7 \%)$ dos infectados sem manifestação neurológica $(\mathrm{p}=0,000)$. O acometimento simétrico das articulações foi observado em $55,5 \%$ dos pacientes com mielopatia e em 30,9\% do grupo sem manifestação neurológica $(\mathrm{p}=0,017)$. Achados de sinovite foram descritos em $25,9 \%$ e em $15,4 \%$ dos pacientes nos grupos com e sem mielopatia, respectivamente $(\mathrm{p}=0,257)$ (Tabela 4$)$.
TABELA 4

MANIFESTAÇÕES ARTICULARES EM 137 INDIVÍDUOS INFECTADOS PELO HTLV-1 COM E SEM MIELOPATIA, DO HUPES-UFBA

\begin{tabular}{|c|c|c|c|c|c|}
\hline \multirow[t]{2}{*}{$\begin{array}{l}\text { Manifestações } \\
\text { articulares }\end{array}$} & \multicolumn{2}{|c|}{$\begin{array}{c}\text { HTLV-1 + } \\
\text { sem mielopatia } \\
(n=110)\end{array}$} & \multicolumn{2}{|c|}{$\begin{array}{c}\text { HTLV-1 + } \\
\text { com mielopatia } \\
(n=27)\end{array}$} & \multirow[t]{2}{*}{ Valor de $\mathrm{p}$} \\
\hline & $n$ & $\%$ & 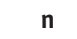 & $\%$ & \\
\hline Dor articular & 59 & 53,6 & 21 & 77,7 & $0,023^{1}$ \\
\hline Monoartralgia & 12 & 10,9 & 2 & 7,4 & $0,737^{3}$ \\
\hline Oligoartralgia & 20 & 18,1 & 3 & 11,1 & $0,566^{3}$ \\
\hline Poliartralgia & 27 & 24,5 & 16 & 59,2 & $0,000^{1}$ \\
\hline Simetria & 34 & 30,9 & 15 & 55,5 & $0,017^{1}$ \\
\hline Rigidez articular & 14 & 12,7 & 12 & 44,4 & $0,000^{1}$ \\
\hline Sinovite & 17 & 15,4 & 7 & 25,9 & $0,257^{3}$ \\
\hline Deformidade articular & 6 & 5,4 & 2 & 7,4 & $0,656^{3}$ \\
\hline Lombalgia & 29 & 26,3 & 13 & 48,1 & $0,028^{1}$ \\
\hline
\end{tabular}

${ }^{1}$ Teste do Qui-Quadrado - Pearson

${ }^{2}$ Teste $t$ de Student

${ }^{3}$ Teste Exato de Fisher

DOENÇAS REUMÁTICAS EM INDIVÍDUOS INFECTADOS PELO HTLV-1 COM E SEM MIELOPATIA ASSOCIADA AO VÍRUS

A freqüência de doenças reumáticas entre os grupos de indivíduos infectados pelo HTLV-1 com e sem mielopatia é mostrada na Tabela 5. No grupo de indivíduos com mielopatia, observou-se que a SS provável foi a doença reumática mais freqüente, tendo ocorrido em $33,3 \%$ dos pacientes. Comparando-se essa freqüência com a encontrada nos infectados pelo HTLV-1 sem manifestação neurológica $(13,6 \%)$, observa-se diferença estatisticamente significativa $(\mathrm{p}=0,024)$. A freqüência de $\mathrm{AR}$ também foi maior $(\mathrm{p}=0,05)$ no grupo de pacientes com mielopatia $(25,9 \%)$, quando comparada com aqueles sem mielopatia (10\%). Nos 110 infectados pelo HTLV-1 sem manifestação neurológica, foram diagnosticados um com LES $(0,9 \%)$ e um com DMTC $(0,9 \%)$. A artropatia relacionada ao HTLV-1 foi suspeitada em $22,2 \%$ e $14,5 \%$, nos grupos com e sem mielopatia, respectivamente $(\mathrm{p}=0,38)$.

\section{DISCUSSÃO}

Nesse estudo foram avaliadas a freqüência e apresentação clínica das diversas doenças reumáticas em indivíduos infectados pelo HTLV-1. A SS provável e a AR, diagnosticadas segundo critérios bem estabelecidos, foram altamente 
freqüentes nesses indivíduos, principalmente naqueles com mielopatia. Suspeita diagnóstica de artropatia associada ao HTLV-1 também ocorreu com alta freqüência na população estudada, independentemente da presença ou não de manifestações neurológicas do vírus.

\section{TABela 5}

FREQÜÊNCIA DE DOENÇAS REUMÁTICAS EM 137 INDIVÍDUOS INFECTADOS COM E SEM MIELOPATIA ATENDIDOS NO HUPES-UFBA

\begin{tabular}{cccc}
\hline & HTLV-1+ & HTLV-1+ & \\
& sem mielopatia & com mielopatia & valor \\
Doenças reumáticas & $(n=110)$ & $(n=27)$ & de $p$ \\
& $n \%$ & $n \%$ &
\end{tabular}

\begin{tabular}{lccccc}
\hline Artrite reumatóide & 11 & 10 & 7 & 25,9 & $0,050^{1}$ \\
Síndrome de Sjögren provável & 15 & 13,6 & 9 & 33,3 & $0,024^{1}$ \\
Lúpus eritematoso sistêmico & 1 & 0,9 & 0 & 0 & $1,000^{1}$ \\
\hline Doença mista do tecido conjuntivo & 1 & 0,9 & 0 & 0 & $1,000^{1}$ \\
\hline Artropatia relacionada ao HTLV-1 & 16 & 14,5 & 6 & 22,2 & $0,380^{1}$ \\
\hline Osteoartrite & 11 & 10 & 4 & 14,8 & $0,495^{1}$ \\
Manifestação articular de & 6 & 5,4 & 0 & 0 & $0,597^{1}$ \\
doença sistêmica & 7 & 6,3 & 0 & 0 & $0,344^{1}$ \\
Síndromes dolorosas periarticulares & 1 & 0,9 & 0 & 0 & $1,000^{1}$ \\
\hline Febre reumática & & & & &
\end{tabular}

Em estudos recentes, tem sido considerado um potencial artritogênico para o HTLV- ${ }^{(16)}$, sendo descrito um tropismo do vírus pelas células sinoviais ${ }^{(17,18)}$. No presente estudo, as manifestações articulares foram achados freqüentes em indivíduos infectados pelo HTLV-1. Quando avaliamos os aspectos reumatológicos da infecção pelo HTLV-1 na população avaliada, a frequiência da sintomatologia clínica de poliartralgia foi de 31,4\%. Em estudo realizado em Tsushima, uma ilha localizada ao noroeste da ilha Kujushu, no Japão, onde $26,1 \%$ da população encontram-se infectados pelo HTLV-1, a incidência de sintomas de poliartrite foi de $37 \%{ }^{(3)}$.

Dentre as doenças reumáticas auto-imunes relacionadas à infecção pelo HTLV-1, têm sido descritas $S S^{(5,19)}, \operatorname{AR}^{(20,21,22)}$, polimiosite $^{(23)}$ e $\operatorname{LES}^{(24)}$, além da artropatia relacionada ao HTLV-1 (APAH) ${ }^{(25)}$.

No único estudo realizado no Brasil sobre a prevalência de HTLV-1 em pacientes com doença difusa do tecido conjuntivo, Lonzetti et al ${ }^{26)}$ (1999) observaram sorologia positiva para HTLV-1/2 por ELISA em 5 de 69 casos de AR (7\%), enquanto a positividade observada no grupo controle de doadores de sangue foi de $1,27 \%(\mathrm{p}<0,05)$. Nesse mesmo estudo, em uma subpopulação de 33 casos de LES, não foi en- contrado nenhum caso de soropositividade para HTLV-1/2. Por outro lado, Nelson et a ${ }^{(27)}$ observaram soropositividade para HTLV-1 em alguns pacientes com LES, dermato/polimiosite ou AR, testados por ELISA, porém quando utilizaram as técnicas de Western Blotting ou reação de polimerase em cadeia (PCR), não confirmaram tal achado.

Em relação à SS, Eguchi et al ${ }^{(6)}$, em 1992, relataram que a taxa de prevalência estimada para esta síndrome em doadores de sangue soropositivos foi de 3,2\% em uma das áreas endêmicas para infecção pelo HTLV-1, no Japão. Nakamura et $\mathrm{I}^{(28)}$, em 1997 , relataram uma alta soroprevalência do HTLV-l em pacientes do gênero feminino com SS, em área endêmica do Japão. Adicionalmente, anticorpos salivares da classe IgA específicos para o vírus foram comumente identificados em pacientes soropositivos para HTLV-1 com SS. Esses achados sugerem uma estreita relação entre infecção pelo HTLV-1 e SS em áreas endêmicas, e que o HTLV-1 deve participar da patogênese da síndrome.

Portanto, a alta freqüência de SS provável encontrada na população estudada $(17,5 \%)$ está de acordo com os dados de literatura que também documentaram uma associação entre essa síndrome e a infecção pelo HTLV- $\mathbf{l}^{(5,19}$, ${ }^{29)}$. Avaliando-se, nesse estudo, a freqüência da SS provável, de acordo com a presença de manifestações neurológicas, observou-se freqüência maior da doença no grupo de indivíduos com mielopatia, quando comparado com os infectados pelo HTLV-1 sem manifestações neurológicas. Esses achados estão de acordo com estudos prévios ${ }^{(5,29,30)}$ que, comparando grupos de indivíduos infectados pelo HTLV-1 com e sem manifestações neurológicas, encontraram alta prevalência de SS no grupo de pacientes com mielopatia.

A AR foi uma das doenças reumáticas auto-imunes mais freqüentes no presente estudo (13,1\%). Entretanto, apenas em 3 dos 18 pacientes foi observado FR positivo. Alterações radiológicas características também foram encontradas em uma minoria desses pacientes. Em nenhum dos pacientes avaliados foram identificadas manifestações extra-articulares da doença, a exemplo de nódulos subcutâneos. Isso pode sugerir que a doença tenha menor gravidade quando associada ao HTLV-1, embora não seja o esperado, desde que a resposta induzida pelo vírus seja predominantemente do tipo $\operatorname{Th}^{(8,31)}$, e a patogênese da AR envolve também a resposta Thl com alta produção de TNF- $A^{(32)}$, o que, juntos, contribuiriam para a maior gravidade da $\mathrm{AR}$. $\mathrm{O}$ fato de a $\mathrm{AR}$ ter sido mais freqüente nos pacientes com mielopatia reforça a idéia de que os mediadores inflamatórios que levam ao aparecimento da 
mielopatia também contribuem para o desenvolvimento da AR. Não se pode, entretanto, afastar que a freqüência elevada de AR no grupo de indivíduos com mielopatia associada ao vírus, pode ter sido por confusão no diagnóstico diferencial entre AR e artropatia associada ao HTLV-1, uma vez que esta artropatia pode apresentar-se com um padrão indistinguível da $\mathrm{AR}^{(33)}$. A maior associação entre HTLV-1 e doenças difusas do tecido conjuntivo (DDTC) no grupo de pacientes com mielopatia poderia também estar relacionada a fatores virais, a exemplo da virulência e imunogenicidade, ou fatores do hospedeiro, a exemplo da predisposição genética.

O HTLV-l é o primeiro retrovírus descrito com potencial para induzir proliferação em células sinoviais humanas, sendo, portanto, um agente provável causador de $\operatorname{artrite}^{(34)}$. No presente estudo, os pacientes que, após exclusão das diversas doenças reumáticas, foram diagnosticados como APAH eram indivíduos relativamente jovens (idade média e desvio padrão de $42,9 \pm 9,1$ ), com queixa de oligoartralgia envolvendo predominantemente grandes articulações de membros inferiores.

Em trabalho de revisão, Masuko et al ${ }^{(34)}$, em 2003, ponderam que é extremamente difícil afirmar se o paciente com artrite é portador de AR clássica concomitante com a infecção pelo HTLV-1 ou se o vírus, por si só, é que está sendo responsável pela artrite.

No que concerne ao LES, no único caso identificado no estudo, em relação às alterações do vírus, observou-se manifestação cutânea atípica, gerando confusão diagnóstica por longa data. A doença foi considerada de evolução benigna, com envolvimentos cutâneos, hematológicos e articular e com FAN fracamente positivo. O LES caracteriza-se por induzir hiperreatividade de células B com hipergamaglobulinemia e a formação de auto-anticorpos patogênicos e nos pacientes infectados pelo HTLV-1, sendo o vírus um indutor da resposta do tipo Thl, essa pode se opor à produção de anticorpos e, por conseguinte, prevenir o aparecimento do LES ou diminuir a gravidade da doença. A baixa freqüência de LES nos indivíduos infectados pelo HTLV-1 nesse estudo, fala a favor de que o vírus não induz ao aparecimento da mesma, diferentemente do que acontece com AR e SS, cuja freqüência foi elevada na casuística desse estudo. Deste modo, assim como na maioria dos trabalhos descritos na

\section{REFERENNCIAS}

1. Eguchi K, Origuchi T, Takashima H, et al: High Seroprevalence of Anti-HTLV-1 Antibody in Rheumatoid Arthritis. Arthritis Rheum 39: 463-6, 1996.

2. Nishioka K, Kitajima I, Yamamoto K, et al: Novel mechanism of synovial proliferation caused by human T Leukemia/lymphotropic literatura $^{(35,36)}$, não foi possível estabelecer associação entre infecção pelo HTLV-1 e LES.

Em uma paciente infectada pelo HTLV-1, foi diagnosticada doença mista do tecido conjuntivo, caracterizada pela combinação de manifestações clínicas do LES (fotossensibilidade, lesões discóides, poliartrite, anemia, leucopenia e FAN positivo) e de polimiosite (diminuição de força muscular proximal associada às alterações de enzimas musculares) e pela presença de anticorpo contra ribonuclease (anti-RNP). O quadro clínico foi marcado pelo envolvimento cutâneo, articular e predominantemente muscular da DMTC. Na evolução clínica foi observada uma tendência à recorrência da atividade inflamatória da doença. Houve melhora da sintomatologia, após introdução de prednisona e difosfato de cloroquina. Nessa paciente, a infecção pelo HTLV-1 pode ter tido papel importante na patogênese da DMTC, entretanto estudos posteriores serão necessários para comprovar esta associação.

Nesse estudo, a freqüência de OA em indivíduos infectados pelo HTLV-1 foi relativamente baixa, comparando-se ao estudo prévio, que encontrou uma prevalência de OA em cerca de $16,19 \%$ em população da América Latina ${ }^{(37)}$.

Diante dos resultados encontrados nesse estudo que reiteram os dados de literatura, sugere-se que em indivíduos infectados pelo HTLV-1, particularmente naqueles com mielopatia, deve-se atentar para um possível desenvolvimento de doenças reumáticas auto-imunes. Por outro lado, em pacientes com doenças reumáticas, a exemplo de $A R$, provenientes de áreas com alta prevalência de infecção pelo HTLV-1, deve-se realizar a pesquisa do vírus, pela possibilidade do uso de imunobiológicos para o tratamento dessas doenças alterar a resposta imune e as manifestações clínicas do HTLV-1.

\section{AGRADECIMENTOS}

Os autores agradecem à Dra. Aurélia Porto, Coordenadora do Ambulatório de HTLV-1, do HUPES da UFBA, pela cooperação e à Dilma Simplícia da Paixão pelo apoio técnico.

Declaramos a inexistência de conflitos de interesse.

virus type 1. Arthritis Rheum 34: S33, 1991.

3. Motokawa S, Hasunuma T, Tajima K et al: High prevalence of arthropathy in HTLV-1 carriers on a Japanese island. Ann Rheum Dis 55: 193-5, 1996.

4. Nishioka K: HTLV-I arthropathy and Sjogren syndrome. J Acquir Immune Defic Syndr Hum Retrovirol 13: 557-62, 1996. 
5. Vernant JC, Buisson G, Magdeleine J, et al: T-lymphocyte alveolitis, tropical spastic paresis, and Sjogren syndrome. Lancet 1: 177,1988

6. Eguchi K, Matsuoka N, Ida H, et al: Primary Sjögren's syndrome with antibodies to HTLV-1: clinical and laboratory features. Ann Rheum Dis 51: 769-76, 1992.

7. Terada K, Katamine S, Eguchi K, et al: Prevalence of serum and salivary antibodies to HTLV-1 in Sjogren 's syndrome. Lancet 344: 1116-9, 1994

8. Carvalho EM, Bacellar O, Porto AF, et al: Cytokine profile and immunomodulation in asymptomatic human T-lymphotropic virus type 1-infected blood donors. J Acquir Immune Defic Syndr 27: $1-6,2001$

9. Dourado I, Galvâo-Castro B: Human T cell Lymphotropic virus in Brazil: current situations in the area with the highest prevalence. AIDS Res Human Retroviruses 17: 17, 2001

10. Kurtzke JF: Further notes on disability evaluation in multiple sclerosis, with scale modifications. Neurology (Minneap) 15: 654-61,1965.

11. Vitali C, Bombardieri S, Jonssonn R, et al: Classification Criteria for Sjögren's Syndrome: a revised version of the European Criteria proposed by the American - European Consensus Group. Ann Rheum Dis 61: 554-8, 2002.

12. Tan EM, Cohen AS, Fries JF et al: Special Article: The 1982 revised criteria for the Classification of Systemic Lupus Erythematosus. Arthritis Rheum 25: 1271-7, 1982.

13. Hollsberg P, Hafler DA: Seminars in Medicine Beth Israel Hospital. Boston Pathogenesis of Disease Induced by Human Lymphotropic Virus Type I Infection. N Engl J Med 328: 1173-82, 1993.

14. Arnett FC, Edworth SM, Bloch DA, et al: The American Rheumatism Association 1987 revised criteria for Classification of Rheumatoid Arthritis. Arthritis Rheum 31: 315-24, 1988.

15. Targoff IN, Miller FW, Medsger TA et al: Classification Criteria for the Idiopathic Inflammatory Myopathies. Curr Opin Rheumatol 9: 527-35, 1997.

16. Habu K, Nakayama-Yamada J, Asano M, et al: The human $\mathrm{T}$ cell leukemia virus type 1 -tax gene is responsible for the development of both inflammatory polyarthropathy resembling rheumatoid arthritis and non-inflammatory ankylotic arthropathy in transgenic mice. J Immunol 162: 2956-63, 1999

17. Kitajima I, Yamamoto K, Sato K: Detection of human T cell lymphotropic virus type 1 proviral DNA and its gene expression in synovial cells in chronic inflammatory arthropathy. J Clin Invest 88: 1315-22, 1991 .

18. Yin W, Hasunuma T, Kobata T, et al: Synovial hyperplasia in HTLV-1 associated arthropathy is induced by tumor necrosis factor-alpha produced by HTLV-1 infected CD68+ cells. J Rheumatol 27: 874-81, 2000.

19. Mariette X, Agbalika F, Zucker-Franklin D, et al: Detection of the tax gene of HTLV-1 in labial salivary glands from patients with Sjogren's syndrome and other diseases of the oral cavity. Clin Exp Rheumatol 18: 341-7, 2000.

20. Wilder RL: Hypothesis for retroviral causation of rheumatoid arthritis. Curr Opin Rheumatol 6: 295-9, 1994.

21. Starkebaum G, Shasteen NM, Fleming-Jones RM, et al: Sera of patients with rheumatoid arthritis contain antibodies to recombinant human T-lymphotropic virus type I/II envelope glycoprotein p21.Clin Immunol Immunopathol 79: 182-8, 1996.

22. Zucker-Franklin D: Non-HIV retroviral associations with rheumatic disease. Curr Rheumatol Rep 2 : 156-62, 2000.

23. Sherman PM, Amin RM, Rodgers-Johnson PEB, et al: Identification of human $\mathrm{T}$ cell leukemia-lymphoma virus type I antibodies, DNA, and protein in patients with polymyositis. Arthritis Rheum 38: 690-8, 1995.

24. Adelman MK, Marchalonis JJ: Endogenous Retroviruses in Systemic Lupus Erythematosus: candidate lupus viruses. Clin Immunol 102: 107-16, 2002.

25. Nishioka K, Maruyama I, Sato K, et al: Chronic inflammatory arthropathy associated with HTLV-I. Lancet i: 441, 1989.

26. Lonzetti LS, Menna-Barreto M, Schoeler M, et al: Anticorpos "anti-human T lymphotropic" virus tipo 1 e 2 (HTLV-1/2) em pacientes com artrite reumatóide. Rev Bras Reumatol 39: 211-6, 1999.

27. Nelson PN, Lever AM, Bruckner FE, et al: Polymerase chain reaction fails to incriminate exogenous retroviruses HTLV-1 and HIV-1 in rheumatological diseases although a minority of sera cross react with retroviral antigens. Ann Rheum Dis 53: 749-54, 1994

28. Nakamura H, Eguchi K, Nakamura T, et al: High prevalence of Sjogren's syndrome in patients with HTLV-1 associated myelopathy. Ann Rheum Dis 56: 167-72, 1997.

29. Izumi M, Nakamura H, Nakamura T, et al: Sjogren's Syndrome (SS) in patients with Human T Cell Leukemia Virus 1 Associated Myelopathy:Paradoxical Features of the Major Salivary Glands Compared to Classical SS. J Rheumatol 26: 2609-14, 1999.

30. Nakamura H, Kawakami A, Tominaga M, et al: Relationship between Sjogren's syndrome and human T-lymphotropic virus type I infection: follow-up study of 83 patients. J Lab Clin Med 135: 139-44, 2000.

31. Santos SB, Porto AF, Muniz AL, et al: Exacerbated inflammatory cellular immune response characteristics of HAM/TSP is observed in a large proportion of HTLV-I asymptomatic carriers. BMC Infect Dis 4: 7, 2004

32. Butrimiene I, Jarmalaite S, Ranceva J, et al: Cytokine Profiles in Patients with Chronic and Acute Reactive Arthritis. Rheumatology (Oxford) 43: 1300-4, 2004.

33. Sato K, Maruyama I, Maruyama Y, et al: Arthritis in patients infected with human T lymphotropic virus type I. Clinical and immunopathologic features. Arthritis Rheum 34: 714-21, 1991.

34. Masuko K, Kato T, Nishioka K: Virus-associated Arthritis. Best Practice \& Research Clinical Rheumatology 17: 309-18, 2003.

35. Murphy EL Jr, De Ceulaer K, Williams W, et al: Lack of relation between human T-lymphotropic virus type I infection and systemic lupus erythematosus in Jamaica, West Indies. J Acquir Immune Defic Syndr 1: 18-22, 1988.

36. Bailer RT, Lazo A, Harisdangkul V, et al: Lack of evidence for human $\mathrm{T}$ cell lymphotropic virus type 1 or 2 infection in patients with systemic lupus erythematosus or rheumatoid arthritis. J Rheumatol 21: 2217-24, 1994.

37. Maldonado NG: Epidemiology of osteoarthritis in Latin America Rev Bras Reumatol 34: 261-6, 1994. 